\title{
Improving the Cercospora Leaf Spot Management Model for Sugar Beet in Minnesota and North Dakota
}

\author{
J. Khan, L. E. del Río, and R. Nelson, Department of Plant Pathology, North Dakota State University, Fargo 58105; \\ and M. F. R. Khan, North Dakota State University and University of Minnesota
}

\begin{abstract}
Khan, J., del Río, L. E., Nelson, R., and Khan, M. F. R. 2007. Improving the Cercospora leaf spot management model for sugar beet in Minnesota and North Dakota. Plant Dis. 91:11051108 .

Management of Cercospora leaf spot, caused by Cercospora beticola, is necessary for the economic production of sugar beet (Beta vulgaris). The objectives of this study were to evaluate the impact of two relative humidity thresholds ( 87 and $90 \%$ ) on the daily infection values (DIVs) used to determine when fungicide applications were required, to determine whether current Cercospora management recommendations for northern areas of Minnesota and North Dakota could be used by growers in the southern areas of these states, and to compare the utility of calendar-based fungicide applications with the Cercospora management model. Research was conducted in Breckenridge, MN and St. Thomas, ND in 2003 and 2004. Fungicide applications significantly $(P=0.05)$ reduced maximum disease severity $\left(\mathrm{y}_{\max }\right)$ and area under the disease progress curve (AUDPC) when compared with the nontreated control at both locations during 2003 and 2004. Fungicides applied according to DIVs calculated at $\mathrm{RH} \geq 87 \%$ or $\mathrm{RH}>90 \%$ gave similar results. The mandatory second fungicide application 14 days after the first application for southern areas did not significantly decrease disease severity or AUDPC, or improve root yield or recoverable sucrose compared with treatments without the mandatory application. This research illustrates that a DIV calculated at $\mathrm{RH} \geq 87 \%$ would result in similar timing of fungicide applications compared with DIVs calculated at RH $>90 \%$. The results further show that the recommendation of fungicide applications at initial symptom and subsequent applications based on DIV and disease severity should be used for both northern and southern growers. Finally, this research showed that fungicide applications based on the Cercospora management model provided similar, effective disease control with fewer fungicide applications compared with calendar-based applications.
\end{abstract}

Additional keywords: data loggers, epidemiology, polycyclic, temperature

Cercospora leaf spot, caused by Cercospora beticola Sacc., is the most economically damaging foliar disease of sugar beet, Beta vulgaris L., worldwide (3). In the United States, Cercospora leaf spot is most destructive in relatively warm and humid conditions $(6,17)$. In Minnesota and North Dakota, losses from Cercospora leaf spot in 1998 were estimated at \$113 million from incomplete control resulting in reduced yield and from fungicides application costs (1). Losses of 30 to $48 \%$ in recoverable sucrose are common under uncontrolled moderate to heavy disease pressure, and relative dollar losses have been reported as high as $43 \%$ $(10,12,13,19)$. Cercospora leaf spotinfected sugar beet also had increased concentrations of impurities resulting in higher processing costs and reduced ex-

\section{Corresponding author: M. F. R. Khan \\ E-mail: Mohamed.khan@ndsu.edu}

Accepted for publication 27 March 2007.

doi:10.1094/PDIS-91-9-1105

(C) 2007 The American Phytopathological Society tractable sucrose $(12,13,19,20)$. In Minnesota and North Dakota, sugar beet roots are stored in ventilated or frozen piles for up to 8 months. Roots of diseased plants do not store as well as healthy roots in storage piles (20).

After the Cercospora leaf spot epidemics of sugar beet during 1981 in Minnesota and North Dakota (23), the epidemiology of $C$. beticola was investigated. As a result, a Cercospora leaf spot prediction model was developed by Shane and Teng (18). Their model combined greenhouse data with information developed by Wallin and Loonan (21). The model comprises two integrally related components, percent severity of the disease obtained from field monitoring, and a Cercospora advisory system based on weather information. The model provides information to help with timely application of fungicides, rather than relying on a fixed-calendar schedule. Ideally, disease monitoring should begin at canopy closure, usually in July, and continue weekly until mid-September. The canopy is considered closed when more than $90 \%$ of plants from adjoining rows are touching. The Cercospora advisory describes the potential for infection by $C$. beticola that existed during the previous 48 $\mathrm{h}$ and is based on daily infection values (DIVs). The DIV indicates how favorable the temperature and relative humidity $(\mathrm{RH})$ were for Cercospora infection on a particular day. DIV ranges from 0 to 7 . If the sum of DIVs from two consecutive days is less than six, equal to six, or more than six, the potential for infection is considered unfavorable, marginal, or favorable for infection, respectively $(18,23)$.

The Cercospora leaf spot prediction model (18) was summarized by Jones and Windels (4) into a management model that provides recommendations for managing Cercospora leaf spot in Minnesota and North Dakota. Based on locations relative to the Polk-Norman county line, Minnesota and North Dakota sugar beet growing areas were divided into northern and southern areas. Growers south of the PolkNorman county line, or southern areas, should apply fungicide initially at a disease severity level of $0.01 \%$, which is equivalent to one lesion per lower leaf, and a second application 14 days after triphenyltin hydroxide (TPTH) or 10 days after mancozeb use, with subsequent applications based on DIV and disease severity for a particular calendar date. Growers north of the Polk-Norman county line, or northern areas, should apply fungicide initially at a disease severity level of $0.01 \%$, with subsequent applications based on DIV and disease severity for a particular calendar date. These disease severity levels were set at $0.01 \%$ for July, 0.03 and $0.10 \%$ for early and late August, respectively, and 0.10 and $0.20 \%$ for early and late September, respectively. Recommendations for northern areas did not include a mandatory second application because disease pressure was historically lower than in southern areas.

Sugar cooperatives and their growers have modified some of the management recommendations and methodology used in obtaining weather data over the years (23). For example, sugar cooperatives recommend that the first fungicide application be made after symptoms initially are observed in the factory district rather than at $0.01 \%$ disease severity, because the latter involved time consumed scouting. After 1998, less than $1 \%$ of treated acres received mancozeb, but TPTH was still widely used (14). As a result, the mandatory second fungicide application was recommended 14 days after the first appli- 
cation. In addition, sugar cooperatives have used $\mathrm{RH} \geq 87 \%$ instead of $\mathrm{RH}>90 \%$ in calculating DIV because anecdotal evidence suggested that this results in DIVs that would better reflect field conditions (23). However, no research was ever conducted to determine whether DIVs calculated at $\mathrm{RH} \geq 87 \%$ would result in a greater number of fungicide applications than when calculated at $\mathrm{RH}>90 \%$.

In the late 1990 s and early 2000 , Cercospora leaf spot disease severity in sugar beet was higher at Breckenridge (south) than at St. Thomas (north), resulting in more fungicide applications in the south $(2,10,14)$. In 1998, for example, fungicides were applied an average of 8.52 times per field in Chippewa County, south of the Polk-Norman County line, whereas 2.28 applications per field were applied in Pembina County, north of the PolkNorman County line (2). Consequently, the Cercospora management model (4) recommendations to apply the first fungicide at initial symptoms followed by a mandatory second application 14 days later for growers south of the Norman-Polk county line was considered necessary and prudent at that time. In 1999, the United States Environmental Protection Agency granted a special request (a Section 18 label) that allowed growers to use tetraconazole (Eminent) for Cercospora leaf spot control. Growers alternated tetraconazole with TPTH from 1999 to 2002 to effectively control the disease. Consequently, the average number of fungicide applications on sugar beet fields in Minnesota and North Dakota was reduced from 3.74 in 1998 to 2.8 in 2002 (14). In the process of controlling Cercospora leaf spot, growers drastically reduced production of secondary inoculum. As such, by 2003 , the mandatory fungicide application 14 days after the first application for growers in southern areas was no longer considered necessary.

Because Cercospora leaf spot pressure has declined in Minnesota and North Dakota over the years, an important question is whether both northern and southern area growers should use a single disease management guideline. If so, southern-area growers could reduce the number of applications by at least one, and the use of one recommendation for all growers will help to simplify the model and avoid misunderstandings.

Table 1. Dates of cumulative daily infection values (cDIVs) $\geq 7$ at relative humidity $(\mathrm{RH}) \geq 87 \%$ for two consecutive days in sugar beet fields at Breckenridge and St. Thomas during 2003 and 2004 ${ }^{\mathrm{a}}$

\begin{tabular}{lccccc}
\hline & \multicolumn{4}{c}{ Dates in month } \\
\cline { 2 - 3 } \cline { 6 - 6 } Months & Breckenridge & St. Thomas & & Breckenridge & St. Thomas \\
${$\cline { 2 - 3 }$} }$ & - & $15,16,26$ & & $\mathbf{4}, 10,21$ & $3,10,19,21$ \\
August & $6,11,18,20,26$ & 6 & & $2,3,8,26$ & 8 \\
September & 11 & 11 & & $1,5, \mathbf{1 0}$ & 3,4 \\
\hline
\end{tabular}

a - Indicates that cDIV $\geq 7$ did not occur at this location and bold indicates that cDIV $\geq 7$ did not occur at $>90 \%$ RH.

In addition, although most growers were using some aspects of the Cercospora management model in determining timing for fungicides, $13 \%$ of growers surveyed indicated the use of four or more applications in 2002 (14), when inoculum pressure in commercial fields was low. The survey showed that growers started spraying in late June and early July and, since growers typically stop spraying in late August or early September, the observed number of applications suggests growers were primarily using fixed-calendar-day applications.

The objectives of this research were to (i) evaluate the efficacy of fungicide application schedules developed using DIV calculated at $\mathrm{RH} \geq 87 \%$ and $\mathrm{RH}>90 \%$, (ii) determine whether the recommendation for timing of fungicide applications for northern areas can be used for southern areas of Minnesota and North Dakota, and (iii) compare the utility of calendar-based applications with the Cercospora management model.

\section{MATERIALS AND METHODS}

Trials to address all objectives were conducted in sugar beet fields at Breckenridge, $\mathrm{MN}$ (south of the Polk-Norman county line) and St. Thomas, ND (north of the Polk-Norman county line) in 2003 and 2004. All experiments were arranged in a randomized complete block design with four replicates, except at St. Thomas in 2004, where only three replicates were seeded. In 2003, treatments at Breckenridge and St. Thomas included an nontreated control; a calendar-based fungicide schedule that started upon detection of initial disease symptoms and continued with applications every 14 days until early September; the southern management program, which called for the first fungicide application upon detection of initial disease symptoms followed by a mandatory second application 14 days later and subsequent applications when a twoconsecutive-days cumulative DIV (cDIV) was $\geq 7$ calculated using $\mathrm{RH} \geq 87 \%$; and the northern management program, which is similar to the southern program but without the mandatory second application. Another treatment, the northern management program based on DIV calculated using $90 \%$ RH instead of $87 \%$ as threshold, was included at St. Thomas. These

1106 Plant Disease /Vol. 91 No. 9 treatments were repeated at both locations in 2004.

Experimental plots were planted with Beta 3800, a sugar beet cultivar susceptible to Cercospora leaf spot (15), on 10 to 16 May 2003 and 26 to 28 April 2004. Each plot was $3.3 \mathrm{~m}$ wide and $9.0 \mathrm{~m}$ long, containing six rows of sugar beet plants 0.55 $\mathrm{m}$ apart. Terbufos was applied at $3.7 \mathrm{~kg}$ a.i $\mathrm{ha}^{-1}$ in-furrow at planting time to control sugar beet root maggot (Tetanops myopaeformis Von Röder). Weeds were controlled using recommended herbicides (7), cultivation, and hand weeding. Plots were thinned to 86,450 plants $\mathrm{ha}^{-1}$ when plants were at the four-leaf stage. Data loggers (HOBO; Onset Computer Corporation, Bourne, MA) were set up at canopy height at each location to record hourly air temperature $\left({ }^{\circ} \mathrm{F}\right)$ and $\mathrm{RH}(\%)$ for calculation of DIV. Rows one and six of plots were inoculated manually in the first week of July using dried infected leaves obtained from Betaseed nursery in Shakopee, MN, where no fungicides were applied. Leaves were mixed with talc (2:1 by weight) and applied at $5.6 \mathrm{~kg} \mathrm{ha}^{-1}$.

In all studies, the fungicides used for disease control were tetraconazole (triazole, Eminent 125 SL; Sipcam Agro USA, Inc.) at $0.11 \mathrm{~kg}$ a.i. ha ${ }^{-1}$ in alternation with pyraclostrobin (strobilurin, Headline 2.09 EC; BASF) at $0.17 \mathrm{~kg}$ a.i. $\mathrm{ha}^{-1}$. Fungicides were applied to the middle four rows of each plot with a four-nozzle boom sprayer calibrated to $690 \mathrm{KPa}$ pressure that delivered spray solution at $187 \mathrm{~L} \mathrm{ha}^{-1}$.

Data collection and analyses. Cercospora leaf spot severity data were collected on the middle two rows of each treatment using the Kleinwanzlebener Saatzucht (KWS) scale (11), ranging from 1 to 9 , in which $1=$ no Cercospora leaf spot symptoms, 3 = leaf spots on the older leaves, 5 $=$ leaf spots coalescence to form small necrotic areas, $7=$ death of older leaves and leaf spot progression to the inner leaves, and $9=$ death of all leaves and initiation of new foliage. Cercospora leaf spot severity data were collected weekly from row closure to harvest in both years. The middle two rows of each plot were harvested mechanically and weighed for root yield in the second half of September 2003 and late September 2004. From each treatment, 12 randomly selected roots were analyzed for recoverable sucrose at the American Crystal Sugar Company Quality Tare Laboratory, East Grand Forks, MN.

Analysis of variance was conducted using SAS (Statistical Analysis System, Cary, NC) to determine the effects of various treatments on maximum disease severity $\left(\mathrm{y}_{\max }\right)$, area under disease progress curve (AUDPC), root yield, and recoverable sucrose. The least significance difference at $P=0.05$ was calculated to compare differences in $\mathrm{y}_{\max }$, AUDPC, root yield, and recoverable sucrose among the treatments. 


\section{RESULTS}

Conditions for disease development, as measured by the number of times when DIVs for two consecutive days were equal to or greater than 7 , were similar across locations in both years (Table 1). The number of days when DIVs were equal to or greater than 7 calculated using either $\mathrm{RH} \geq 87 \%$ or $>90 \%$ as thresholds also were similar. Consequently, the number of fungicide treatments applied as recommended and the timing of the applications were the same for each location (Tables 2 and 3). As a result, $y_{\max }$, AUDPC, root yield, and recoverable sucrose were similar when fungicides were applied based on cDIV calculated at $\mathrm{RH} \geq 87 \%$ compared with fungicides applied based on cDIV calculated at $\mathrm{RH}>90 \%$.

Plots that received fungicide applications from any management program had significantly less disease and yielded significantly more than plots that were not sprayed at both locations and years (Tables 2 and 3 ).

Plots managed following the northern disease management program produced $\mathrm{y}_{\max }$, AUDPC, root yield, and recoverable sucrose at Breckenridge, a southern loca- tion, similar to those managed following the southern disease management; however, the latter resulted in an additional fungicide application during both years (Tables 2 and 3). Similarly, at St. Thomas, a northern location, both programs produced similar $\mathrm{y}_{\max }$, AUDPC, root yield, and recoverable sucrose. Contrasting with the results from the southern locations, at St. Thomas both management programs resulted in a similar number of fungicide applications in 2003; however, in 2004, plots managed following the southern program received an additional fungicide application (Tables 2 and 3).

Plots that received calendar-based fungicide applications that started upon first detection of disease and continued every 14 days until early September just prior to harvest had disease, AUDPC, root yield, and recoverable sucrose similar to plots treated following southern disease management programs at both locations and years. Calendar-based fungicide treatments also resulted in trends of disease severity and yield similar to the northern management program at St. Thomas in both 2003 and 2004. At Breckenridge, calendar-based fungicide regimes resulted in significantly lower disease severity at harvest in both 2003 and 2004 compared with the northern management program, where DIV was calculated at $\mathrm{RH} \geq 87 \%$ (Tables 2 and 3 ). On average, using calendar-based fungicide applications resulted in one additional application compared with the southern management program and two additional applications compared with the northern management program.

\section{DISCUSSION}

In this research, disease development generally was slow at the beginning of the season and reached maximum severity $\left(\mathrm{y}_{\max }\right)$ late in the season, usually in September. Because $C$. beticola is a polycyclic pathogen, several cycles of inoculum are produced during the sugar beet growing season that infect healthy tissues of the plant. One cycle of sporulation can last for about 12 days under field conditions (22). However, intensity of disease severity is highly dependent upon favorable environmental conditions. Field and greenhouse studies show that temperatures below $10^{\circ} \mathrm{C}$ suppress development of Cercospora leaf spot $(16,18,21)$. Intensity of disease severity in 2003 at both locations was higher

Table 2. Numbers of fungicide applications and disease and yield measures from different management programs at Breckenridge, MN and St. Thomas, ND in $2003^{\mathrm{a}}$

\begin{tabular}{|c|c|c|c|c|c|c|c|c|c|c|}
\hline \multirow[b]{2}{*}{ Treatments $^{\mathbf{b}}$} & \multicolumn{5}{|c|}{ Breckenridge (southern location) } & \multicolumn{5}{|c|}{ St. Thomas (northern location) } \\
\hline & Sprays & $\mathbf{y}_{\max }$ & AUDPC & Yield & $\mathbf{R S}$ & Sprays & $\mathbf{y}_{\max }$ & AUDPC & Yield & $\mathbf{R S}$ \\
\hline Nontreated control & 0 & 7.5 & 36.1 & 33.1 & 4.22 & 0 & 7.0 & 31.4 & 36.5 & 5.52 \\
\hline Southern $(\mathrm{RH} \geq 87 \%)$ & 3 & 2.4 & 16.7 & 45.2 & 6.09 & 2 & 1.8 & 13.8 & 61.6 & 8.32 \\
\hline Northern $(\mathrm{RH} \geq 87 \%)$ & 2 & 2.6 & 17.4 & 45.5 & 5.82 & 2 & 2.1 & 15.4 & 59.8 & 8.62 \\
\hline Northern $(\mathrm{RH}>90 \%)$ & - & - & - & - & - & 2 & 2.3 & 15.5 & 57.8 & 8.32 \\
\hline Calendar-based spraying & 4 & 1.9 & 15.1 & 48.8 & 6.17 & 4 & 2.3 & 15.7 & 57.6 & 8.19 \\
\hline $\operatorname{LSD}(P=0.05)$ & $\ldots$ & 0.7 & 1.9 & 6.2 & 0.84 & $\ldots$ & 1.2 & 2 & 8.1 & 0.86 \\
\hline
\end{tabular}

${ }^{\text {a }}$ Sprays $=$ number of sprays; $y_{\max }=$ maximum amount of disease severity recorded during the growing season using a 1-to-9 scale, where 1 indicates no leaf spot and 9 indicates dead outer leaves with inner leaves severely damaged and growth of new leaves; AUDPC $=$ area under the disease progress curve calculated from initial symptoms until harvest; Yield (Mg/ha); RS = recoverable sucrose $(\mathrm{Mg} / \mathrm{ha})$; and $-=$ data not collected at this location and year.

${ }^{\mathrm{b}}$ The southern management program (Southern) starts upon detection of initial symptoms. A mandatory second application is made 14 days later. Thereafter, applications are made when the cumulative daily infection value from two consecutive days reaches 7 in a scale of 0 to 14 . Daily infection values are generated using relative humidity $(\mathrm{RH}) \geq 87 \%$ or $\mathrm{RH}>90 \%$ as threshold. The northern management program (Northern) is similar to the Southern program, but there is no mandatory second application. Calendar-based spraying starts at detection of initial symptoms and continues every 14 days until early September. Treatments were arranged in a randomized complete block design with four replicates at Breckenridge and three replicates at St. Thomas. LSD = least significant difference.

Table 3. Numbers of fungicide applications and disease and yield measures from different management programs at Breckenridge, MN and St. Thomas, ND in $2004^{\mathrm{a}}$

\begin{tabular}{|c|c|c|c|c|c|c|c|c|c|c|}
\hline \multirow[b]{2}{*}{ Treatments $^{\mathbf{b}}$} & \multicolumn{5}{|c|}{ Breckenridge (southern location) } & \multicolumn{5}{|c|}{ St. Thomas (northern location) } \\
\hline & Sprays & $\mathbf{y}_{\max }$ & AUDPC & Yield & $\mathbf{R S}$ & Sprays & $\mathbf{y}_{\max }$ & AUDPC & Yield & $\mathbf{R S}$ \\
\hline Nontreated control & 0 & 5.1 & 23.6 & 46.6 & 6.05 & 0 & 4.50 & 21.1 & 39.9 & 5.16 \\
\hline Southern $(\mathrm{RH} \geq 87 \%)$ & 3 & 1.9 & 14.7 & 62.0 & 8.49 & 3 & 1.67 & 15.0 & 49.5 & 7.38 \\
\hline Northern (RH $\geq 87 \%)$ & 2 & 2.4 & 15.2 & 59.1 & 8.02 & 2 & 2.17 & 15.6 & 48.6 & 7.29 \\
\hline Northern (RH > 90\%) & 2 & 2.1 & 15.3 & 62.3 & 8.59 & 2 & 2.17 & 15.7 & 49.3 & 7.04 \\
\hline Calendar-based spraying & 4 & 1.6 & 14.6 & 59.8 & 8.81 & 4 & 1.67 & 14.8 & 51.7 & 7.45 \\
\hline $\operatorname{LSD}(P=0.05)$ & $\ldots$ & 0.6 & 1.2 & 4.5 & 0.78 & $\ldots$ & 0.66 & 1.8 & 4.2 & 0.40 \\
\hline
\end{tabular}

a Sprays = number of sprays; $y_{\max }=$ maximum amount of disease severity recorded during the growing season using a 1-to- 9 scale, where 1 indicates no leaf spot and 9 indicates dead outer leaves with inner leaves severely damaged and growth of new leaves; AUDPC = area under the disease progress curve calculated from initial symptoms until harvest; Yield (Mg/ha); and $\mathrm{RS}=$ recoverable sucrose $(\mathrm{Mg} / \mathrm{ha})$.

b The southern management program (Southern) starts upon detection of initial symptoms. A mandatory second application is made 14 days later. Thereafter, applications are made when the cumulative daily infection value from two consecutive days reaches 7 in a scale of 0 to 14 . Daily infection values are generated using relative humidity $(\mathrm{RH}) \geq 87 \%$ or $\mathrm{RH}>90 \%$ as threshold. The northern management program (Northern) is similar to the Southern program, but there is no mandatory second application. Calendar-based spraying starts at detection of initial symptoms and continues every 14 days until early September. Treatments were arranged in a randomized complete block design with four replicates at Breckenridge and three replicates at St. Thomas. LSD $=$ least significant difference. 
than in 2004. The unseasonably low temperatures that prevailed in 2004 at both locations during the growing season, particularly in August, was probably the main factor responsible for low disease severity. The average daily temperatures at Breckenridge and St. Thomas were 15 and $16^{\circ} \mathrm{C}$ in 2004 , respectively, compared with 22 and $22^{\circ} \mathrm{C}$, respectively, in 2003 .

Fungicide treatments provided significantly better disease control and higher yield and recoverable sucrose compared with the nontreated control. This result was consistent with research conducted by Shane and Teng (19), who showed that no significant yield loss occurred when Cercospora leaf spot severity was low at harvest. The fungicides used, tetraconazole and pyraclostrobin, consistently provide excellent Cercospora leaf spot control $(5,8-10)$.

Consistently similar results in terms of disease control, root yield, and recoverable sucrose were achieved across years and locations when initial fungicide applications were based on initial detection of symptoms with subsequent applications based on DIV calculated at $\mathrm{RH} \geq 87 \%$ or $\mathrm{RH}>90 \%$. This was due in part to the fact that the number and timing of fungicide applications recommended by the different management programs were the same when DIVs $\geq 7$ were calculated using RH $\geq 87 \%$ or RH $>90 \%$ as thresholds. Further, on most days, whenever RH reached $87 \%$, it also reached $90 \%$, and cDIVs were the same $92 \%$ of the time. Results of our study showed that using the northern disease management program to control Cercospora leaf spot at both northern and southern locations was a better option than the southern management program, because it allowed for fewer fungicide applications while preserving yield and recoverable sucrose. Applying fewer fungicides will reduce production cost for growers in the south, and also lower selection pressure for the development of resistance in $C$. beticola. As such, the Cercospora management model should be modified to recommend that the first fungicide treatment be applied at initial detection of symptoms, with subsequent applications based on DIV and disease severity for growers in northern and southern areas in Minnesota and North Dakota.

The use of two or three timely fungicide applications based on the management model provided effective disease control in inoculated plots that reached moderate to high disease levels when left untreated. Under the moderate to heavy disease pressure created by the artificial inoculations made in the experimental plots, the use of four fungicide applications was not necessary for adequate and acceptable disease control. Thus, under lower disease pressure in a commercial field setting, the fourth calendar application also would be expected to be unwarranted, especially if the fields are planted to more tolerant cultivars than the one used in these studies.

\section{ACKNOWLEDGMENTS}

We thank the North Dakota State Board of Agricultural Research and Education, Sugar Beet Research and Education Board of Minnesota and North Dakota, Sipcam, and Cerex Agri for providing funding and support for this research; and sugar beet researchers at North Dakota State University for their assistance in maintenance and harvesting of plots.

\section{LITERATURE CITED}

1. Cattanach, A. 1999. Managing Cercospora leaf spot tolerance or resistance to fungicide. American Crystal Sugar Company Agnotes Issue no. 364.

2. Dexter, A. G., and Luecke, J. L. 1999. Survey of fungicide use in sugarbeet in eastern North Dakota and Minnesota in 1998. 1999 Sugarbeet Res. Ext. Rep. N. D. State Univ. Fargo 29:229-233.

3. Holtschulte, B. 2000. Cercospora beticolaworldwide distribution and incidence. Pages 516 in: Cercospora beticola Sacc. Biology, Agronomic Influence and Control Measures in Sugar Beet 2000, Vol. 2. Advances in Sugar Beet Research. M. J. C. Asher, B. Holtschulte, M. Richard Molard, F. Rosso, G. Steinrücken, and R. Beckers, eds. International Institute for Beet Research, Brussels.

4. Jones, R. K., and Windels, C. E. 1991. A management model for Cercospora leaf spot of sugarbeets. Univ. Minn. Ext. Circ. AG-FO5643-E.

5. Karaoglanidis, G. S., and Bardas, G. 2006. Control of benzimidazole- and DMI-resistant strains of Cercospora beticola with strobilurin fungicides. Plant Dis. 90:419-424.

6. Kerr, E. D., and Weiss, A. 1990. Fungicide efficacy and yield responses to fungicide treatments based on predictions of Cercospora leaf spot of sugar beet. J. Sugar Beet Res. 27:58-71.

7. Khan, M., ed. 2003. Pages 22-47 in: 2003
Sugarbeet Production Guide. North Dakota State University and University of Minnesota Extension Services.

8. Khan, M., Smith, L., Bredehoeft, M., and Roehl, S. 2001. Cercospora leaf spot control in eastern North Dakota and Minnesota in 2000. 2000 Sugarbeet Res. Ext. Rep. N. D. State Univ. Fargo 31:303-310.

9. Khan, M., Smith, L., Bredehoeft, M., and Roehl, S. 2003. Cercospora leaf spot control in Eastern North Dakota and Minnesota in 2002. 2002 Sugarbeet Res. Ext. Rep. N. D. State Univ. Fargo 33:223-230.

10. Khan, M. F. R., and Smith, L. J. 2005. Evaluating fungicides for controlling Cercospora leaf spot on sugar beet. Crop Prot. 24:79-86.

11. Kleinwanzleber Saatzucht Ag. Einbeck. 1970. Cercospora. Kleinwanzleber Saatzucht Ag. Einbeck Rabbethge and Geisecke.

12. Lamey, H. A., Cattanach, A. W., and Bugbee, W. M. 1987. Cercospora leaf spot of sugarbeet. N. D. State Univ. Ext. Circ. PP-764 Revised.

13. Lamey, H. A., Cattanach, A. W., Bugbee, W. M., and Windels, C. E. 1996. Cercospora leaf spot of sugarbeet. N. D. State Univ. Ext. Circ. PP-764 Revised.

14. Luecke, J. L., and Dexter, A.G. 2003. Survey of fungicide use in sugarbeet in eastern North Dakota and Minnesota in 2002. 2002 Sugarbeet Res. Ext. Rep. N. D. State Univ. Fargo 33:177-181.

15. Niehaus, W. S. 2002. Results of American Crystal's 2001 official coded variety trials. 2001 Sugarbeet Res. Ext. Rep. N. D. State Univ. Fargo 32:333-372.

16. Pool, V. W., and McKay, M. B. 1916. Climatic conditions as related to Cercospora beticola. J. Agric. Res. 6:21-60.

17. Ruppel, E. G. 1986. Cercospora leaf spot. Pages 8-9 in: Compendium of Beet Diseases and Insects. E. D. Whitney and J. E. Duffus, eds. American Phytopathological Society, St. Paul, MN.

18. Shane W. W., and Teng, P. S. 1984. Cercospora beticola infection prediction model. 1983 Sugarbeet Res. Ext. Rep. N. D. State Univ. Fargo 14:174-179.

19. Shane, W. W., and Teng, P. S. 1992. Impact of Cercospora leaf spot on root weight, sugar yield and purity. Plant Dis. 76:812-820.

20. Smith, G. A., and Ruppel, E. G. 1973. Association of Cercospora leaf spot, gross sugar, percentage sucrose and root weight in sugarbeet. Can. J. Plant Sci. 53:695-696.

21. Wallin, J. R., and Loonan, D. V. 1971. Effect of leaf wetness duration and air temperature on Cercospora beticola infection of sugar beet. Phytopathology 61:546-549.

22. Weiland, J. J., and Koch, G. 2004. Sugarbeet leaf spot disease (Cercospora beticola Sacc.). Mol. Plant Pathol. 5:157-166.

23. Windels, C. E., Lamey, H. A., Dave, H., Widner, J., and Knudsen, T. 1998. A Cercospora leaf spot model for sugar beet in practice by an industry. Plant Dis. 82:716-726. 